Discussion Control Banding outcomes have been applied internationally, implemented by national institutes and university programs, and directly transferred into national regulations. RLBMS outcomes can assist in addressing the 2.5 billion workers worldwide without access to OSHH experts, providing a strategy for preventing work-related noncommunicable diseases in EDCs.

\section{HOW TO BE A BETTER FIREFIGHTER? A GUIDELINE TO IMPROVE YOUR PERFORMANCE, TAKING CARE OF YOUR PHYSICAL AND MENTAL HEALTH}

${ }^{1} \mathrm{C}$ Meneses, ${ }^{2} \mathrm{~J}$ Sierra, ${ }^{3} \mathrm{C}$ Porres, ${ }^{3} \mathrm{~L}$ Vela, ${ }^{3} \mathrm{C}$ Guzmán, ${ }^{3} \mathrm{M}$ Hernández, ${ }^{3} \mathrm{E}$ González, ${ }^{3} \mathrm{M}$ Sagastume, ${ }^{4} \mathrm{~L}$ Kurtz. ${ }^{1} A$ lumni, OSH International Master, Ludwig-MaximilliansUniversitat, Munich, Germany. Guatemalan physician; ${ }^{2}$ Chief, Voluntary Firefighters, Guatemala, Guatemala; ${ }^{3}$ San Carlos University, Guatemala, Guatemala; ${ }^{4}$ Coordinator, OSH International Master, Ludwig-Maximillians-Universitat, Munich, Germany

\subsection{6/oemed-2018-ICOHabstracts.672}

Introduction Globally, firefighting is a highly stressful, physical and mental demanding occupation. In a study carried out by the principal author, Guatemalan firefighters suffered from musculoskeletal disorders and distress, mainly because of physical unfitness, inadequate eating habits and violence exposure. A teaching intervention was planned with a component of training and the elaboration of a book, designed for Central American firefighters, with the aim of teaching firefighters how to take care of their physical and mental health. The book is already having direct impact on more than 5,000 Guatemalan firefighters.

Methods The book was planned as a teaching intervention firstly for Guatemalan firefighters and then scope was widened to Central American firefighters. It was conducted using participatory methodology with representatives of firefighters, who designed layout and wrote chapter 1. Collaboration was obtained from toxicology and nutrition experts of Universidad de San Carlos, including senior students, in writing chapters 2, 3 and 4. This University also collaborated in the printing of the first 500 copies. Collaboration was also obtained from Ludwig-Maximillians-Universitat, in writing chapters 5, 6 and 7 , as well as the final revision and layout.

Results The book was electronically issued in 2016 using Ludwig-Maximillians-Universitat networks and hard copies were delivered to Guatemala's firefighters authorities in a formal ceremony on 2017. More than 3000 of copies are waiting to be printed at Universidad de San Carlos de Guatemala.

Conclusion This is a perfect example of a successful teaching intervention, with multicenter collaboration, including universities in Germany and in Guatemala, as well as the direct participation of the targeted population.

\section{A MULTI-DISCIPLINARY, INTER-CONTINENTAL COLLABORATION TO BUILD CAPABILITY IN OCCUPATIONAL HEALTH AMONG HEALTH CARE PROFESSIONALS}

\footnotetext{
${ }^{1}$ Inakshi Naik*, ${ }^{2}$ Ashish Mittal, ${ }^{3}$ Tor Danielson, ${ }^{4}$ Robin Nicholas, ${ }^{5}$ Mahinda Seneviratne. ${ }^{1}$ Formerly South Africa NIOH, Johannesburg, South Africa; ${ }^{2}$ Medical Consultancy ServicesOHS, New Delhi, India; ${ }^{3}$ Oslo University Hospital, Oslo, Norway; ${ }^{4}$ Robin Nicholas Communications, Santa Fe, New Mexico, USA; ${ }^{5}$ SC Occupational Health in Small Scale Enterprises and Informal Sector (SCOHSSEIS), Sydney, Australia
}

10.1136/oemed-2018-ICOHabstracts.673
Introduction The interaction between community, environment and the workplace is crucial in the provision of basic health care services in low resource countries. United Nations' Sustainable Development Goals, strategies of its agencies WHO and ILO and professional bodies such as ICOH and IALI have highlighted the need for capability building and integration in delivering the necessary services to these communities. However, health care professionals, including medical doctors and nurses undergo limited training in occupational health during their professional undergraduate education.

Methods A series of workshops for health care professionals to develop knowledge and basic skills in workplace hazard identification, assessment and control were conducted in India and Malaysia. The multi-disciplinary program involving occupational medicine, hygiene, ergonomics and hazard communication was delivered by a group of occupational health professionals from five different continents. Their time and resources were provided voluntarily at no cost for the local organisers.

Result The workshops involved interactive group work facilitated by skilled specialists sharing their international experiences, together with demonstration of case studies by local experts. This approach enabled the diverse local health care workers, especially young females, to share the challenges faced in their work and develop valuable skills that can be applied to their work.

Discussion The success of these workshops has inspired the volunteers to explore the potential for developing a more sustainable 'academy' for capability building in basic occupational health. This model for a social enterprise in low resource countries through collaborating at international level will be presented and discussed.

\section{ARE WE SHIFTING EXPOSURE TO CHEMICAL AGENTS TO WAREHOUSE WORKERS?}

S Verpaele*. Becoh Vzw, Zwijnaarde, Belgium

\subsection{6/oemed-2018-ICOHabstracts.674}

European legislation related to exposure to chemical agents is becoming stricter. REACH and CLP have ensured that more agents are classified as dangerous and there are also more agents end up on authorisation and restricted lists. It is clear that the industry has to deal with this and exposure to chemicals is considered to be under control. The last few years the warehouse workers are worrying more and more about exposure to chemical agents. Deadly accidents with fumigated containers was the trigger but should we worry about that or should we be more aware about chronic exposure to a soup of chemicals? In several countries procedures for measuring sea fright containers are introduced. They are mainly based on non- or semi-selective methods and focus on 16 specific chemical agents and total VOC.

A study in different warehouses showed some remarkable results. Less than $1 \%$ of the total inbound flow was actual fumigated and this was even not deliberately. A shift in personal exposure was seen when having measuring campaigns in winter and in summer. In winter there is more background exposure and in summer the peak exposure when opening a container was higher. Investigation of the procedures that are introduced in several European countries is showing that the need for a proper risk assessment is needed before a safe unloading process can be made. The defined group of 16 chemical agents and the total VOC is far from what is needed to asses workers exposure. 